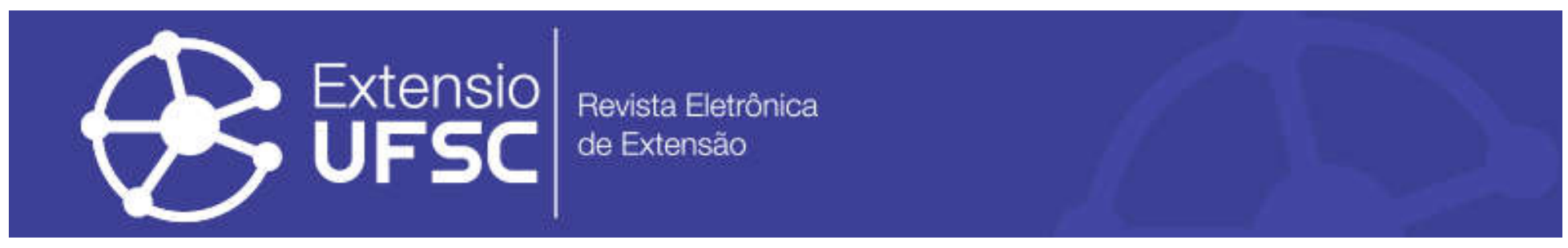

\title{
FOTOEDUCAÇÃO NA PREVENÇÃO DO CÂNCER DE PELE: RELATO DE EXPERIÊNCIA
}

\author{
Julia Victória Azevedo Costa \\ Universidade Federal do Rio de Janeiro \\ juvicosta97@gmail.com \\ Luis Phillipe Nagem Lopes \\ Universidade Federal do Rio de Janeiro \\ luisphillipelopes@hotmail.com \\ Luiz Eduardo Fileto Caldeira \\ Universidade Federal do Rio de Janeiro \\ lzdesigner.18@gmail.com \\ Zaida Maria Faria de Freitas \\ Universidade Federal do Rio de Janeiro \\ zaida@pharma.ufrj.br
}

Mariana Sato de Souza de Bustamante Monteiro

Universidade Federal do Rio de Janeiro mari-sato@hotmail.com

Márcia Maria Barros dos Passos Universidade Federal do Rio de Janeiro mmbpassos@gmail.com

Dalila dos Santos Cerqueira Pinto Universidade Federal do Rio de Janeiro dalila@eba.ufrj.br

Elisabete Pereira dos Santos Universidade Federal do Rio de Janeiro elisabetepharma@gmail.com

\begin{abstract}
Resumo
Introdução: A campanha de fotoeducação, por meio da interação dialógica entre os atores sociais (universidade e escola), pode ser o primeiro passo para o estabelecimento de uma política de educação em saúde. A equipe de saúde da Farmácia Universitária da Universidade Federal do Rio de Janeiro vem desenvolvendo atividades em escolas públicas do município do Rio de Janeiro para a promoção da saúde por meio da educação. Objetivo: compilar e divulgar as atividades do projeto de extensão da Farmácia Universitária da Universidade Federal do Rio de Janeiro em escolas públicas da cidade do Rio de Janeiro. Metodologia: Um levantamento bibliográfico sobre fotoeducação foi realizado e as informações obtidas foram repassadas para graduandos do curso de pintura da Universidade Federal do Rio de Janeiro que participaram de sessões de orientação acerca das ações e, então, elaboraram atividades lúdicas para alunos daquelas escolas. Resultados: Foram realizadas duas campanhas com 75 participantes no total. Considerações finais: As atividades realizadas foram um instrumento de disseminação do conhecimento e possibilitaram acesso à informação aos alunos que participaram do processo, tornando-os transmissores de conhecimento em suas comunidades. Alunos de graduação e pós-graduação foram protagonistas em seu processo formativo e adquiriram responsabilidade social pela inserção das atividades de educação em saúde.

Palavras-chave: Câncer de Pele. Crianças. Escolas Públicas. Fotoeducação. Educação em Saúde.
\end{abstract}

\section{PHOTOEDUCATION IN HEALTH AIMING AT PREVENTING SKIN CANCER: EXPERIENCE REPORT}

\begin{abstract}
Introduction: The photoeducation campaign, through dialogical interaction between social actors (university and school), may be the first step for the establishment of a educational policy towards health care. The health team at the University Pharmacy of the Federal University of Rio de Janeiro has been developing activities in public schools in the city of Rio de Janeiro to promote health through education. Objective: to compile and disseminate the activities of the extension project of the University Pharmacy of the Federal University of Rio de Janeiro in public schools in the city of Rio de Janeiro. Methodology: A bibliographic survey on photoeducation was carried out and the data were passed on to undergraduate students of the painting course at the Federal University of Rio de Janeiro who participated in training sessions, for guidance about the actions, and then developed recreational activities for students from those schools. Results: Two campaigns were carried out with 75 participants in total. Final considerations: The activities were an instrument to spread out knowledge and give access to information to students who participated in the process and made them a source of knowledge within their communities. Undergraduate and graduate students were protagonists in their training process and acquired social responsibility for the insertion of health education activities.
\end{abstract}

Keywords: Skin Cancer. Kids. Public Schools. Photoeducation. Health Education. 
Fotoeducação na prevenção do câncer de pele: relato de experiência

\section{FOTOEDUCACIÓN EN SALUD CON EL FIN DE PREVENIR EL CÁNCER DE PIEL: RELATO DE EXPERIENCIA}

Resumen

Introducción: El acceso a la fotoeducación es el primer paso hacia el establecimiento de una política de educación para la salud, representada por la interacción dialógica entre los actores sociales (universidad y escuela). Por lo tanto, los equipos de salud de la Farmacia Universitaria UFRJ (FU-UFRJ) han estado desarrollando actividades en las escuelas públicas de la ciudad de Río de Janeiro, con el fin de establecer una política de educación sanitaria. Objetivo: recopilar y difundir las actividades del proyecto de extensión FU-UFRJ en las escuelas públicas de Río de Janeiro. Metodología: se realizó una encuesta bibliográfica, obteniendo información sobre fotoeducación. Esta información fue transmitida al alumno del curso de Pintura en la UFRJ para desarrollar actividades recreativas. Los estudiantes del equipo participaron en un curso de capacitación, recibiendo orientación sobre las acciones. Resultados: se realizaron dos campañas, 75 estudiantes participaron en las acciones. Consideraciones finales: Las actividades realizadas fueron un instrumento para la difusión del conocimiento y brindaron acceso a la información a los estudiantes que participaron en el proceso, convirtiéndolos en transmisores de conocimiento en sus comunidades. Los estudiantes de pre y posgrado fueron protagonistas en su proceso de formación y adquirieron responsabilidad social para la inserción de actividades de educación en salud.

Palabras clave: Cáncer de Piel. Niños. Escuelas Publicas. Fotoeducación. Educación en Salud. 
Fotoeducação na prevenção do câncer de pele: relato de experiência

\section{INTRODUÇÃO}

O câncer de pele é uma neoplasia com uma fisiopatologia complexa que envolve a proliferação celular e pode ser classificado como melanoma (CPM) e não melanoma (CPNM). As neoplasias de pele são as mais comuns em todo o mundo e sua morbidade tem gerado impactos significativos na saúde pública (DIEPGEN et al., 2012; DE CEBALLOS et al., 2014). Considerando o cenário brasileiro, o CPNM é o mais frequente e corresponde a cerca de $30 \%$ de todos os tumores malignos registrados (INCA, 2019).

O principal fator de risco para a gênese da doença é a exposição a raios ultravioletas (UV) A e B, especialmente nos primeiros 20 anos de idade (DE CEBALLOS et al., 2014), e a principal medida preventiva é evitar exposição prolongada ao sol entre $10 \mathrm{~h}$ e 16h, horário que tem maior incidência da radiação ultravioleta prejudicial à saúde. (INCA, 2019). Tal fato é preocupante, pois as crianças frequentemente praticam atividades ao ar livre na faixa de horário de maior incidência de luz solar, ou seja, elas passam mais tempo expostas aos raios UVA e UVB (THOONEN et al., 2020), o que torna fundamental a orientação e educação da população mais jovem acerca das consequências da exposição incorreta.

A Sociedade Brasileira de Dermatologia (SBD), em 2014, preconizou um consenso de fotoproteção no Brasil, norteando atividades educativas para a redução dos danos causados pela exposição ao sol. Esse compêndio de informações definiu fotoeducação como "um conjunto de ações de caráter educativo, desenvolvido para conscientizar determinado grupo populacional sobre os riscos da exposição inadvertida ao sol e orientar condutas saudáveis em fotoproteção e incentivou a elaboração de atividades de fotoeducação baseadas na faixa etária do público, a fim de obter maior impacto". A SBD afirmou, ainda, que as crianças compõem um grupo mais receptivo às informações de prevenção ao câncer de pele (SCHALKA et al, 2014).

Há uma estreita relação entre Educação em Saúde e promoção da saúde, visto que as ações de atenção à Saúde, além de tratar e/ou prevenir doenças, destinam-se também a promover o crescimento e desenvolvimento infantil, em uma perspectiva de qualidade de vida. Logo, as ações de promoção da saúde devem ser planejadas com estratégias que envolvam a sociedade e família.

No contexto familiar, os pais ou responsáveis provêm os cuidados para o bom desenvolvimento das crianças e detêm um saber que não poderá ser descartado, mas aperfeiçoado e/ou adaptado ao saber científico dos profissionais (GONÇALVES et al., 2008). 
Fotoeducação na prevenção do câncer de pele: relato de experiência

No contexto social, a escola é quem assume um papel preponderante. Segundo a Organização Pan-americana de Saúde - OPS (1995), a promoção da saúde no âmbito escolar deve partir de uma visão integral e multidisciplinar do ser humano, que considera as pessoas em seu contexto familiar, comunitário, social e ambiental. Assim, as ações de promoção de saúde devem desenvolver conhecimentos, habilidades e destrezas para o autocuidado da saúde e a prevenção das condutas de risco em todas as oportunidades educativas, bem como fomentar uma análise sobre os valores, as condutas, condições sociais e os estilos de vida dos próprios sujeitos envolvidos (GONÇALVES et al., 2008).

Faz-se necessário, então, pensar em atividades educativas com foco no processo de ensino-aprendizagem que possibilitem ao indivíduo a capacidade de compreender a informação e desenvolver habilidades que o tornem aprendiz ativo e participante do conhecimento. Portanto, as práticas lúdicas mostram-se eficazes na transmissão de informações e têm um maior interesse, engajamento e motivação do público-alvo (FORTUNATO \& TEICHNER, 2015).

Considerando essas premissas, este trabalho visa a compilação e divulgação das atividades elaboradas pelo projeto de extensão "Fotoeducação: câncer de pele, como evitar?" da Farmácia Universitária da UFRJ (FU-UFRJ), desenvolvido com alunos do ensino fundamental em escolas públicas localizadas na zona oeste do município do Rio de Janeiro.

\section{MATERIAIS E MÉTODOS}

\section{Desenho do estudo}

Um estudo descritivo, tipo relato de experiência (ARAÚJO et al., 2013; BRITO et al, 2019), foi realizado no período de março a dezembro de 2019. As ações de fotoeducação foram realizadas em duas campanhas no Centro Universitário Estadual da Zona Oeste (UEZO). A primeira ação contou com a participação de cerca de 45 alunos do $3^{\circ}$ ano do Ensino Fundamental da Escola Municipal Moacyr Scliar, e a segunda ação contou com a participação de cerca de 30 alunos do $1^{\circ}$ ano do Ensino Fundamental da Escola Municipal Jardim Guararapes, ambas situadas no bairro de Campo Grande, na zona oeste do Rio de Janeiro. Essa divisão foi elaborada para promover a participação de todas as crianças e melhorar o diálogo, a integração, a interação e o relacionamento entre elas e a equipe do projeto, uma vez que turmas reduzidas favorecem os laços entre os estudantes e a troca de saberes e, consequentemente, fortalecem a interação dialógica. 
Fotoeducação na prevenção do câncer de pele: relato de experiência

Essas atividades foram desenvolvidas pelo Projeto de Extensão "Fotoeducação em saúde: câncer de pele, como evitar?” da FU-UFRJ, aprovado no Edital PROFAEX da UFRJ, No 32/2018, sob número de processo (SIGProj N: 297239.1656.62629.01032018). A equipe executora do trabalho e responsável pelas ações nas escolas foi constituída por três estudantes e três professores do curso de Farmácia, dois estudantes do curso de pintura da Escola de Belas Artes e dois farmacêuticos da Farmácia Universitária, todos pertencentes à Universidade Federal do Rio de Janeiro. Durante todas as etapas de elaboração e execução das ações do projeto de extensão, as suas diretrizes (interação dialógica, interdisciplinaridade e interprofissionalidade; impacto de transformação social; indissociabilidade entre ensino, pesquisa e extensão e impacto na formação do estudante) foram aplicadas. Além disso, uma revisão na literatura científica sobre o tema foi realizada em diferentes bases de dados para a elaboração de um material educativo.

\section{Levantamento bibliográfico e produção do material}

Inicialmente, os alunos de graduação do Curso de Farmácia realizaram um levantamento bibliográfico em bases de dados, tais como: Scielo, Portal Regional da Biblioteca Virtual de Saúde (BVS) e Google Scholar. Foram realizadas buscas utilizando os descritores DeCS/MeSH e palavras chave (em português e inglês): fotoeducação, fotoproteção, exposição inadequada ao sol, uso correto de fotoprotetores, skin cancer, kids, public schools, photoeducation e bealth education. As informações obtidas foram selecionadas e sistematizadas sob supervisão dos orientadores do projeto e repassadas aos alunos do curso de pintura da Escola de Belas Artes. Estes, então, criaram atividades lúdicas que visaram o público infantil, como informativos, jogos interativos e desenhos para colorir, além de uma unidade visual de estética criativa, acessível e de fácil entendimento.

Considerando que a ludicidade é um instrumento facilitador da interação entre o profissional da saúde e as crianças (MEDEIROS et al, 2016) e que os alunos deveriam participar ativamente do processo ensino-aprendizagem, optou-se pelo uso de um quebracabeça com diferentes níveis de complexidade, um jogo da memória e desenhos para colorir, além de um informativo autoexplicativo, com figuras e orientações sobre o uso correto de protetor solar e outros temas voltados à correta exposição solar. Os jogos interativos fazem parte do acervo e serão utilizados em outras campanhas. No entanto, o informativo autoexplicativo e os desenhos para colorir foram doados para os participantes ao final da campanha. 
Fotoeducação na prevenção do câncer de pele: relato de experiência

\section{Treinamento com a equipe do projeto}

Com o objetivo de estabelecer uma conduta uniforme nas atividades desenvolvidas nas escolas, a equipe do projeto recebeu treinamento a respeito de adequação da linguagem, práticas de conscientização sobre os riscos da exposição solar e uso correto do protetor solar.

Além disso, foram implementadas rodas de conversas entre os alunos de graduação com a finalidade de esclarecer dúvidas acerca do tema, bem como levantar ideias que tornassem a ação nas escolas do ensino fundamental efetiva para o público infantil.

\section{A campanha educativa}

A campanha foi realizada no período da tarde, de $13 \mathrm{~h}$ às $16 \mathrm{~h}$. Em uma roda de conversa interativa formada pela equipe do projeto e as crianças, perguntas e respostas sobre o tema foram discutidas para elicitar o conhecimento prévio dos alunos. A partir das respostas das crianças, os alunos de graduação complementaram as informações e apresentaram dados presentes nos banners.

Após a roda de conversa, as crianças participaram de uma simulação. Dois bonecos feitos com material sensível à radiação ultravioleta foram submetidos à luz solar, dentre eles somente um utilizava protetor solar. Os alunos puderam observar a formação da cor vermelha no boneco que não usava o produto (Figura 1). Essa atividade foi fundamental para mostrar a importância do protetor solar e sua correta aplicação. Após essa experiência, as crianças brincaram com o quebra-cabeça e o jogo da memória, pintaram um desenho sobre o tema, e receberam um informativo para divulgação do conhecimento e uma amostra grátis do protetor solar manipulado pela FU-UFRJ.

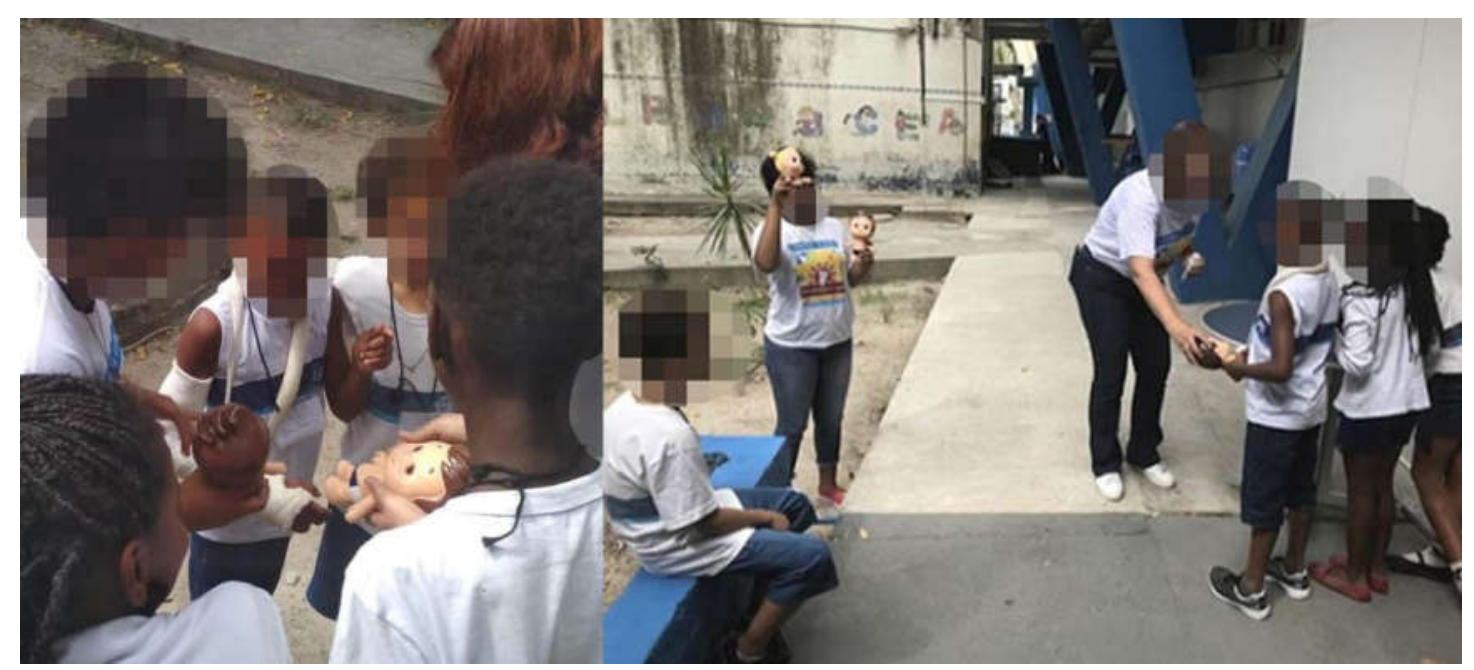

Figura 1 - Atividade sobre o uso correto de protetor solar 
Fotoeducação na prevenção do câncer de pele: relato de experiência

\section{RESULTADOS E ANÁLISES}

Os materiais produzidos (informativos com linguagem adequada ao público infantil sobre fotoeducação, fotoproteção, exposição inadequada ao sol e uso correto de fotoprotetores; banners; jogos interativos e desenhos para colorir) estão ilustrados na Figura 2.

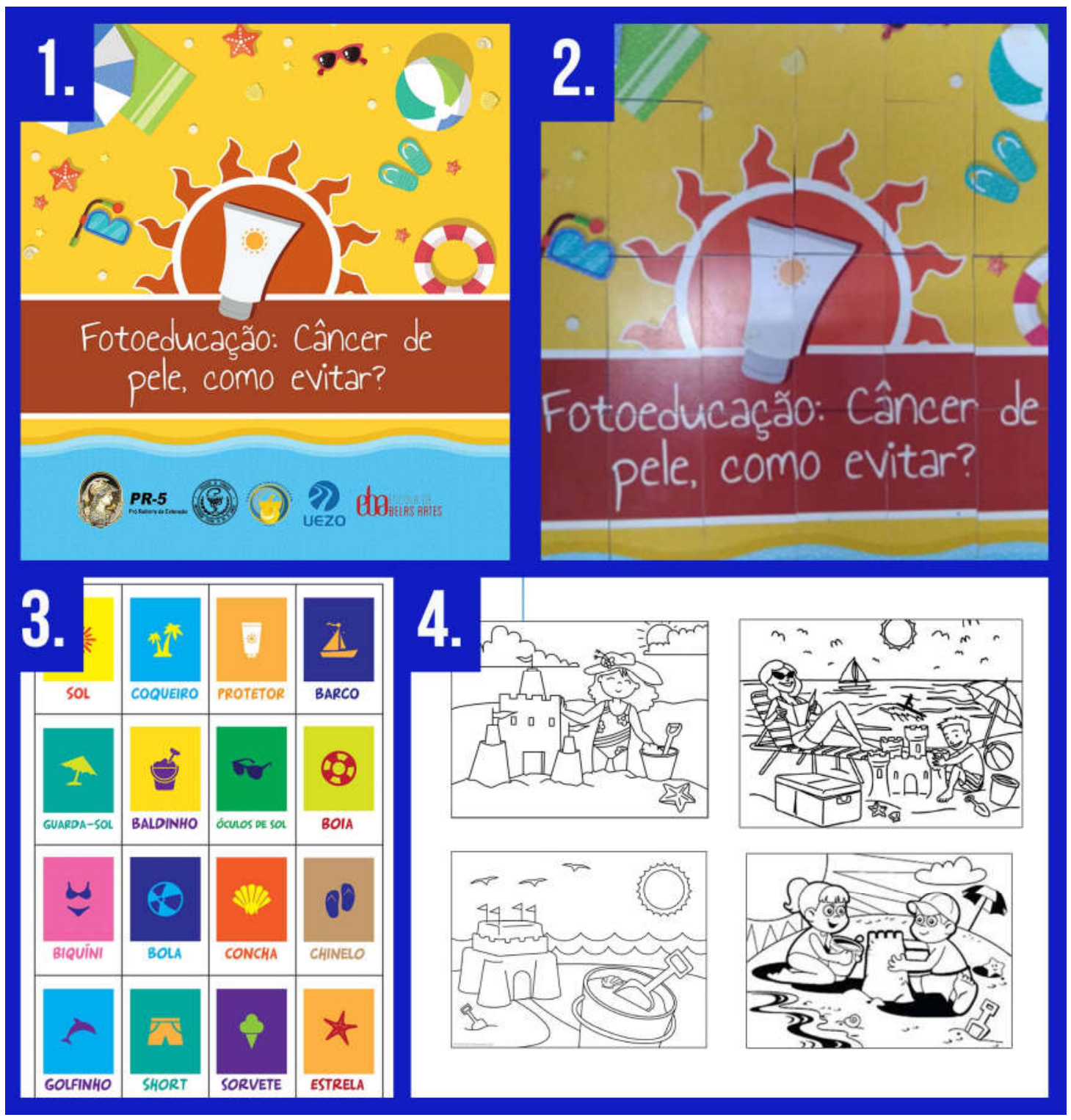

Figura 2 - Materiais produzidos pelos estudantes do Curso de Pintura - EBA/UFRJ para a campanha nas escolas de ensino fundamental. 
Fotoeducação na prevenção do câncer de pele: relato de experiência

A Figura 3 mostra as ações realizadas com as crianças.

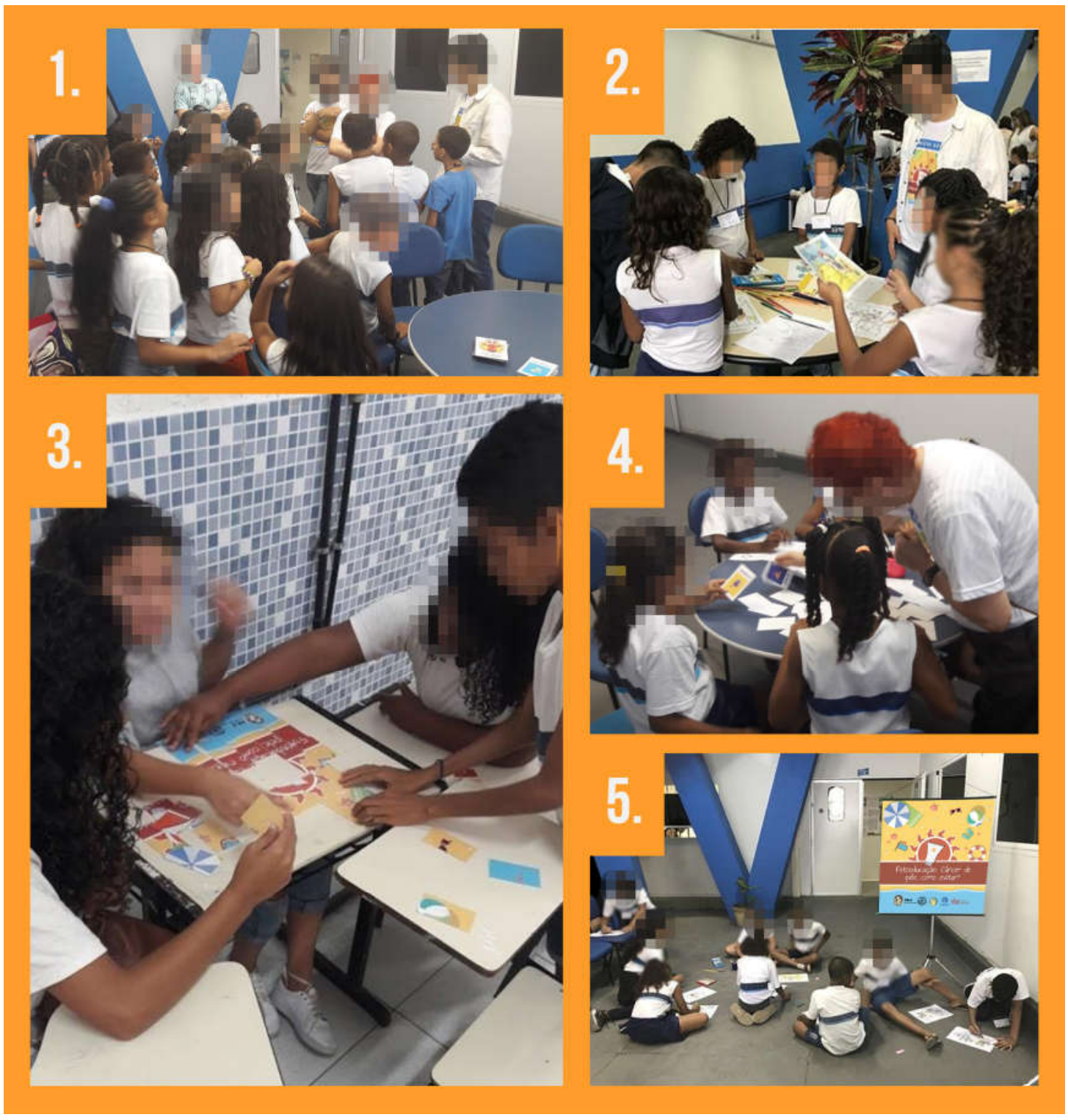

Figura 3. Ações realizadas no projeto.

A interação dialógica entre a Universidade e a sociedade pressupõe simultaneidade, e a efetividade dessa troca necessita da aplicação de metodologias que estimulem a participação e a democratização do conhecimento, como neste projeto, por meio do desenvolvimento de materiais lúdicos (FORPROEX, 2012). A utilização de jogos e brincadeiras é uma estratégia 
Fotoeducação na prevenção do câncer de pele: relato de experiência

ímpar na educação em saúde, pois atrai a atenção, desperta a curiosidade e o interesse, e facilita o entendimento e a adesão de hábitos saudáveis (SOUZA et al., 2010). Dessa forma, as atividades conseguiram disseminar o conhecimento sobre fotoeducação, gerar acesso à informação e promover a educação em saúde.

A escola é um local estratégico para tais ações, especialmente sobre o tema câncer de pele, pois ali as crianças passam parte de seu tempo em atividades sob o sol (DA SILVA \& DO CARMO, 2011). Um estudo avaliando os cuidados de proteção solar e prevenção do câncer de pele em pré-escolares mostrou que o uso de filtro solar é incorreto e insuficiente, e que a exposição ao sol geralmente ocorre em horários inadequados (BATISTA et al., 2013).

Esses dados revelam a importância de atividades de fotoeducação no ambiente escolar para a conscientização dos alunos e, a partir desses, dos pais. Ademais, a adoção de práticas saudáveis adquiridas na escola será tão mais consistente quanto forem o apoio das famílias, professores e direção.

Campanhas que envolvam todos esses atores, como as do projeto de extensão "Fotoeducação: câncer de pele, como evitar?", têm um papel crucial na expansão desse conhecimento, suprindo a carência de informação sobre medidas primárias de proteção solar. As crianças nessas escolas se tornam vetores dessa conscientização, adotam hábitos simples que as protegem da exposição solar incorreta e disseminam conhecimento à família e comunidade ao redor. Nesse sentido, as ações voltadas para a educação e o autocuidado e desenvolvidas nesses ambientes também contribuem para a redução das desigualdades no acesso à informação.

Com isso, consolida-se a diretriz do impacto e a transformação social, que reafirma a Extensão Universitária como mecanismo por meio do qual se estabelece a atuação transformadora, voltada para os interesses e necessidades da população e propiciadora do desenvolvimento social (FORPROEX, 2012).

Ações de intervenção de educação em saúde voltadas para uma exposição solar segura vêm sendo realizadas no Brasil, a exemplo do programa Sol Amigo, realizado desde 2006, que tem por objetivo levar informação à comunidade que não está bem informada sobre os efeitos à saúde decorrente da exposição excessiva ao sol. Outro exemplo vem da Prefeitura de Caxias de Sul, que disponibiliza protetores solares para produtores rurais e população em geral. Apesar dessas ações e da relação bem estabelecida entre exposição ao sol e o câncer de pele, existem poucos estudos sobre os hábitos de proteção solar na primeira faixa etária.

Em se tratando de um país tropical, ressalta-se que o risco de efeitos nocivos da exposição solar é ainda mais elevado devido ao efeito cumulativo. Então, ações de saúde no 
Fotoeducação na prevenção do câncer de pele: relato de experiência

âmbito da fotoproteção feitas hoje em dia são de grande relevância num país com alta incidência de radiação UV e pouco acesso a produtos fotoprotetores num cenário futuro. Portanto, a importância deste estudo para a análise das práticas de proteção solar e para o preenchimento da lacuna de conhecimento a respeito do tema fica notória (BATISTA et al., 2013).

Os estudantes expostos às atividades assumiram um papel ativo no processo de ensinoaprendizagem, descondicionando-se da atitude de mero receptor de conteúdo e buscando conhecimentos relevantes aos problemas e aos objetivos da aprendizagem. Isso contribuiu para uma experiência enriquecedora tanto para eles, quanto para os acadêmicos de Farmácia (SANTOS, 2005). Houve um impacto significativo na formação do aluno de graduação, por meio do seu envolvimento direto nas atividades extensionistas, e um enriquecimento da experiência discente em termos teóricos e metodológicos (FORPROEX, 2012).

Os serviços de saúde vinculados às instituições de ensino apresentam melhores resultados terapêuticos (BOND et al., 2001). Logo, essa ação de extensão pautada na promoção da saúde contribuiu para a divulgação do conhecimento científico e na integralização da criança no papel da promoção da saúde. A extensão universitária tem um papel fundamental na disseminação de conteúdos acadêmicos estabelecendo a troca de saberes sistematizado, acadêmico e popular. As consequências inerentes à prática repercutem na produção do conhecimento resultante do confronto com a realidade brasileira e regional, na democratização do conhecimento acadêmico e na participação efetiva da comunidade na atuação da universidade. Dessa forma, os avanços na área da saúde dependem da transferência de conhecimentos gerados pela academia para evoluir, aprimorar a qualidade da atenção e os resultados terapêuticos, reduzir e/ou prevenir morbimortalidade.

No âmbito do Sistema Único de Saúde, que deve garantir o acesso aos serviços de saúde em todos os níveis de assistência e a integralidade de assistência às ações e serviços preventivos e curativos, individuais e coletivos (REIS et al., 2018), existe uma demanda pela formação de profissionais de saúde que excedam a capacitação técnico-científico, cuja importância é inquestionável, mas não suficiente para a efetivação de práticas de gestão e cuidado em saúde que envolvam os diferentes trabalhadores/usuários/cidadãos. Ademais, a formação de sujeitos comprometidos, éticos e cônscios da sua importância na implementação de mudanças congruentes com os princípios do SUS, capazes de atuar resolutivamente na realidade sanitária na qual estão inseridos pode promover o fortalecimento do SUS e, consequentemente, a diminuição das desigualdades (BISCARDE et al., 2014). 
Fotoeducação na prevenção do câncer de pele: relato de experiência

Esta experiência foi pautada no aprendizado mútuo. Tal estratégia é importante para que a educação em saúde cumpra o seu papel com relevância: melhorar as condições de vida e saúde da população por meio da aprendizagem adequada à sua realidade. Briceno Leon (1996) retrata o processo de educação em saúde com a elaboração de sete teses, duas das quais enfatizam as experiências adquiridas nessas ações: "a ignorância não é um vazio a ser preenchido, mas um cheio a ser transformado" e "não há um que sabe e outro que não sabe, mas dois que sabem coisas diferentes".

Que o método de compartilhamento de saberes e fazeres com a comunidade, esclarecendo sobre os horários que requerem maior cuidado com a exposição solar, medidas de proteção da pele, principais medicamentos que causam sensibilidade ao sol, autoexame, sinais e sintomas na pele causados por reações de fotossensibilidade, entre outros, diminuam a ocorrência do câncer de pele e/ou promovam um diagnóstico precoce.

\section{CONSIDERAÇÕES FINAIS}

O projeto de extensão "Fotoeducação: câncer de pele, como evitar?" elaborou, promoveu, compilou e divulgou atividades voltadas para alunos do ensino fundamental em escolas públicas localizadas na zona oeste do município do Rio de Janeiro. Além do mais, mostrou a necessidade do desenvolvimento de ações em saúde naquelas comunidades.

Com um material atrativo e desenvolvido especificamente, eles, os alunos das escolas públicas, puderam participar ativamente do processo e se tornaram fonte de conhecimento dentro de suas comunidades.

As atividades realizadas foram um instrumento de disseminação do conhecimento e possibilitaram acesso à informação aos alunos que participaram do processo, tornando-os fonte de conhecimento em suas comunidades.

Os estudantes de graduação e pós-graduação se tornaram protagonistas do seu processo de formação e adquiriram responsabilidade social por meio da inserção de atividades de educação em saúde.

\section{AGRADECIMENTOS}

Os autores agradecem ao Programa Institucional de Fomento Único de Ações de Extensão (PROFAEX) da Universidade Federal do Rio de Janeiro - UFRJ pela concessão das bolsas de extensão, e à direção da Faculdade de Farmácia pelo apoio e transporte para as escolas públicas. 
Fotoeducação na prevenção do câncer de pele: relato de experiência

\section{REFERÊNCIAS}

ARAÚJO, M. G., CASSIANO, A.N.; HOLANDA, C.S.M.; MOREIRA, P.V.S.Q.; GIOVANNINI, P.E. Educação em saúde no ensino infantil: metodologias ativas na abordagem da ação extensionista. Revista de Enfermagem UFPE on line, v. 7, n. 1, p. 30613, 2013.

BATISTA, T. et al. Avaliação dos cuidados de proteção solar e prevenção do câncer de pele em pré-escolares. Revista Paulista de Pediatria, v. 31, n. 1, p. 17-23, 2013.

BISCARDE, D. G. dos S.; PEREIRA-SANTOS, M.; SILVA, L. B.. Formação em saúde, extensão universitária e Sistema Único de Saúde (SUS): conexões necessárias entre conhecimento e intervenção centradas na realidade e repercussões no processo formativo. Interface-Comunicação, Saúde, Educação, v. 18, p. 177-186, 2014.

BOND, C. A.; RAEHL, C. L.; FRANKE, T. Medication errors in United States hospitals. Pharmacotherapy: The Journal of Human Pharmacology and Drug Therapy, v. 21, n. 9, p. 1023-1036, 2001.

BRICEÑO-LEÓN, R.. Siete tesis sobre la educación sanitaria para la participación comunitaria. Cadernos de Saúde pública, v. 12, n. 1, p. 7-30.

BRITO, L. F. S.; CAMARGO, J. G.; SANTOS, V. F.; PIRES, C. R. F.; SOUSA, D. N.; KATO, H. C. A. Metodologias lúdicas e educação alimentar e nutricional para promover o consumo de pescado em escolares. Extensio: R. Eletr. de Extensão, Florianópolis, v. 16, n. 34, p. 126-142, 2019.

CONSENSO BRASILEIRO DE FOTOPROTEÇÃO, 1 ed., 2014, Rio de Janeiro. Anais Brasileiros de Dermatologia, Rio de Janeiro: SBD, 89 (6):1, 2014

DA SILVA, L. R.; DO CARMO FRANÇA-BOTELHO, A.. Proteção solar para crianças: estudo preliminar sobre conhecimentos e atitudes dos pais. Ciência $\&$ Saúde, v. 4, n. 1, p. 2 6, 2011.

DE CEBALlOS, A. G. da C. et al. Exposição solar ocupacional e câncer de pele não melanoma: estudo de revisão integrativa. Revista Brasileira de Cancerologia, v. 60, n. 3, p. 251-258, 2014.

DE MEDEIROS, E. R. et al. O cuidado à criança na educação infantil: um relato de experiência. Revista Científica de Enfermagem, v. 6, n. 16, p. 32-47, 2016.

DE SOUZA, M. M. A. et al. A inserção do lúdico em atividades de educação em saúde na creche-escola Casa da Criança, em Petrolina-PE. Revista de Educação do Vale do São Francisco-REVASF, v. 1, n. 1, p. 39 a 49, 2010.

DIEPGEN, TL1 et al. Occupational skin cancer induced by ultraviolet radiation and its prevention. British Journal of Dermatology, v. 167, p. 76-84, 2012. 
Fotoeducação na prevenção do câncer de pele: relato de experiência

FÓRUM DE PRÓ-REITORES DE EXTENSÃO DAS INSTITUIÇÕES PÚBLICAS DE EDUCAÇÃO SUPERIOR BRASILEIRA (FORPROEX). Política Nacional de Extensão Universitária. Porto Alegre: UFRGS/Pró-Reitoria de Extensão, 2012.

FORTUNATO, I.; TEICHNER, O. T. Refletindo sobre a gameficação e suas possibilidades na educação. Revista Brasileira de Iniciação Científica, v. 2, n. 3, 2015.

GONÇALVES, F. D. et al. A promoção da saúde na educação infantil. InterfaceComunicação, Saúde, Educação, v. 12, n. 24, p. 181-192, 2008.

INSTITUTO NACIONAL DO CÂNCER (INCA), Câncer de pele não melanoma, 2019. Disponível em:https://www.inca.gov.br/tipos-de-cancer/cancer-de-pele-nao-melanoma>. Acesso em: 17 de abr. de 2019.

MOURA, J. B. V. S. et al. Perspectiva da epistemologia histórica e a escola promotora de saúde. História, Ciências, Saúde-Manguinhos, v. 14, n. 2, p. 489-501, 2007.

OPS. ORGANIZAÇÃO PANAMERICANA DE SAÚDE. Educación para la salud: un enfoque integral. Washington: OPS, 1995. (Série HSS/SILOS, n.37).

Programa Sol Amigo. [capturado em 17 abr. 2020]; Disponível em: http://www.solamigo.org.

REIS, D. O. et al. Políticas Públicas de Saúde: Sistema Único de Saúde. 2018. Disponível em:

https://www.unasus.unifesp.br/biblioteca_virtual/esf/2/unidades_conteudos/unidade04/uni dade04.pdf. Acesso em 14 de fev. de 2021.

SANTOS, S. S. A integração do ciclo básico com o profissional no Curso de Graduação em Medicina: uma resistência exemplar. Rio de Janeiro: Papel \& Virtual, 2005.

SCHALKA, S.; STEINER, D.; RAVELLI, F.N.; STEINER, T.; TERENA, A.C.; MARÇON, C.R. Brazilian Consensus on Photoprotection. Anais Brasileiro Dermatologia. V. 89, v. 6 Suppl 1:S6-73, 2014.

THOONEN, K; OSCH, L.V.; VRIES, H.; JONGEN, S.; SCHNEIDER, F. Are Environmental Interventions Targeting Skin Cancer Prevention among Children and Adolescents Effective? A Systematic Review. Int J Environ Res Public Health. V. 14, v. 17 Suppl. 2:529, 2020.

Recebido em: 09/07/2020

Aceito em: 31/03/2021 